\title{
Implementation Of Carlson Survey Software2009 In Survey Works And Comparison With CDS Software
}

\author{
Mohamed Faraj EL Megrahi \\ Assistant Lecturer, Higher Institute for Building Trades and Construction, Benghazi, Libya.
}

A R T I C L E I N F O

Article history:

Received: 15 January, 2017

Accepted: 12 February, 2017

Online: 25 February, 2017

Keywords:

Survey Automation

Cds Civil Design Software

Carlson Survey Software

Data Processing And Collection

Methods

\begin{abstract}
A B S T R A C T
The automation surveying is one of the most influential changes to surveying concept and profession has had to go through, this has taken effect in two major courses, hardware (instrumentation used in data collection and presentation), and the software (the applications used in data processing and manipulation). Automation is majorly computer based and just like all such systems is subject to improvement often; this is manifested in the new kinds of instrumentation models every few years such as total station and newer versions of software's. The software that has the potential to completely affect survey automation is Carlson Surveying Software. This when coupled with total station as data processing and collection methods respectively; is capable of greatly improving productivity while reducing time and cost required in the long run. However, it is only natural for users to desire a competent software and be able to choose from what is available on the market based on guided research and credible information from previous researches. Such studies not only help in choice of software but are also handy when it comes to testing approaches and recommending improvements based on advantages and disadvantages to the manufacturers to help in advancement in the software industry for better and more comfortable use. The expected outcome of the research is a successful implementation of Carlson survey 2009 software in survey works and a comparison with other existing software like Civil Design Software (CDS) was highlighted its advantages and disadvantages.
\end{abstract}

\section{Introduction}

Enwinding surveys establish points by travers bassline or other methods to obtained information required for engineering designs and to set out construction from design drawing by used of these control points. The nature of the data required to be collected, the techniques, instrumentation to be used and the use allocated to the data collected all have a role they play in determining the nature and type of surveying to be carried out. With the new age of computer, there have been drastic and yet amazing changes in profession as pertaining instrumentation and computation and data processing . Total station have replaced plan tables and software has replaced the unwieldy mathematical computations that were previously done through analogue methods. In fact the practice of surveying and mapping has

Tel.:+00218925481959; e-mail: mohamedbaleid79@gmail.com changed very greatly with the automation nowadays and this has given an all new view to surveying as a discipline. Investments in the surveying filed by major commercial interests such as big companies (e.g. LICECA,TOPCON,TRIMBLE and SOKIA) seek to improve their knowledge in these fields such as Global Navigation Satellite Systems (GNSS),Geographic Information System (GIS). The total station is one such advancement in instrumentation that is currently top notch because it contains software components coupled with both an electronic theodolite and distomat, the instrument is very handy in surveys today and is preferred by many surveyors . A difference among all popular survey software on market today like Civil Design Software (CDS), surveying and engineering LISCAD software, Pythagoras, Microsurvey, are: the vary cost to graphic capability function and user friendliness as well as their respective ability to handle large data and heavy projects. Carlson survey 2009 
software is one of the newly developed software made by Carlson Software Inc from united states. This software consists of program integrated with AutoCAD into one package. The capacity of the software has been improved to meet the requirements of a task and fulfill the satisfaction of the user. The software was designed in a complete package that an output needs not to export to another application to produced final results.

A complete survey automation system is basically a combination between the total station and survey software in order to process survey data up to the production of final results in form of maps graph in their softcopy and or hardcopy .where there are many applications software's on the market today that help in engineering survey works it's important to implementation and assess each software carefully to fully understand its operations, advantages and disadvantages. This paper aims to carry out the implementation of Carlson survey software for engineering survey works and compare it to CDS software.

In this research covers a case study in which the sample data by total station from a special selected site in the vicinity of University Technology Malaysia using Carlson surveying 2009 software for processing and manipulation of data. For this study comparison between CDS software and Carlson survey software and demonstrate how suitable each is when used complementarity to total station equipment also this software is a pivot of further assessment into the approaches of adopting and implementation of Carlson survey software in Libya based engineering survey work with hope of improving the survey methodology in Libya from basic to more advanced automation methods.

\section{Data Acquisition:}

Data be used for the research project was acquired using a LICA TPS307 series instrument with control being obtained from GPS observation. This instrument is a high quality electronic total station designed for the engineering and construction site surveying. The GPS observation were carried out prior to the topographic survey using a Trimble 4800 receiver for a very short baseline of two point UTM01 and station 2 STN2 which were to be used as control and orientation later in the process of traversing and detailing. The data from the GPS observation was downloaded and processed in Trimble total control software. the GPS benchmark (UTM 01) that was using to establish coordinates of another point for orientation . An area of the whole place was to be about $800 \mathrm{~m}^{2}$ having a total perimeter of about $400 \mathrm{~m}$. For data collection it would be necessary for at least one total station (LICA TPS307, the trigger button functionality and endless motion screws as well as many tripods to enable us to set up many simultaneous targets, as well as 3 or 4 reflector prism ranging. For determination the coordinate of point we use from GPS needed 3 station, first the total station was put on known position point (UTM01) then entered the coordinate of UTM01 as the station point in total station. second was interring the coordinate of second point as back sight point. Then set the horizontal angle zero in the back-sight direction. For gathering coordinate of required points commence to producing detailed plan should gather the coordinate of every detail in this site. Although gathering the detail depended on the scale of the plan. The sit contained building, tree, float way, street, tower and gathered the coordinate of all of them. Also for creating the counter coordinate gathered of topographies. After that because the other required points were at the back of the building there was need to change the position of the total station on the second station and continued the observation from there. In this station was got other corner of the building float way and terrain. The last station was station three in whish gathered the coordinate of one big tree, tower and terrain.

\section{Results and Analysis}

The results are presented in two forms; those obtained from CDS data processing and those obtained using Carlson survey 2009 software. The detailed plans are DTM in both cases are drawn based on the same study area but processed separately in the two different software. The results as obtained from the methodology followed in this research include detailed plans, DTMs in the form of contours, TIN and GRID. The detailed plan as showed in the Figure 1 represent the area of study (observatory area - University Technology Malaysia). The initial CDS results, after being exported to AutoCAD for editing and improvement to be carried out on the detailed plan is presented as in Figure 2. The 3D presentation of TIN models in CDS software is also represented in Figure 3, which attempts to create a better height and visual interpretation of the topography for users of CDS software.

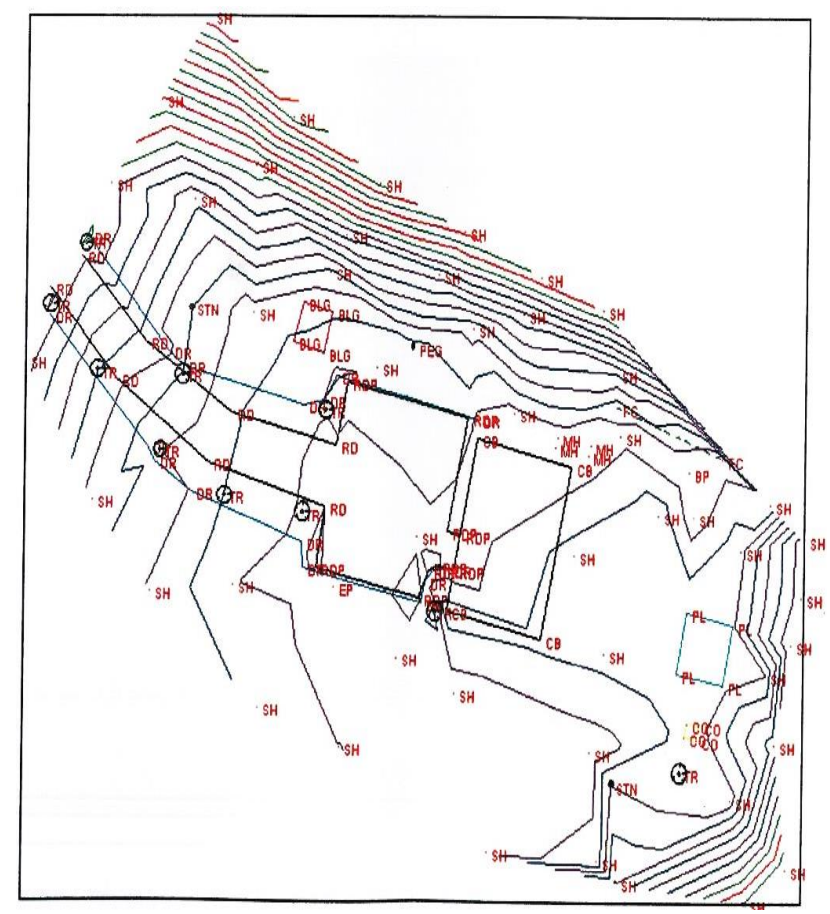

Figure 1 Detail plan from Civil Design Survey Software automation. 


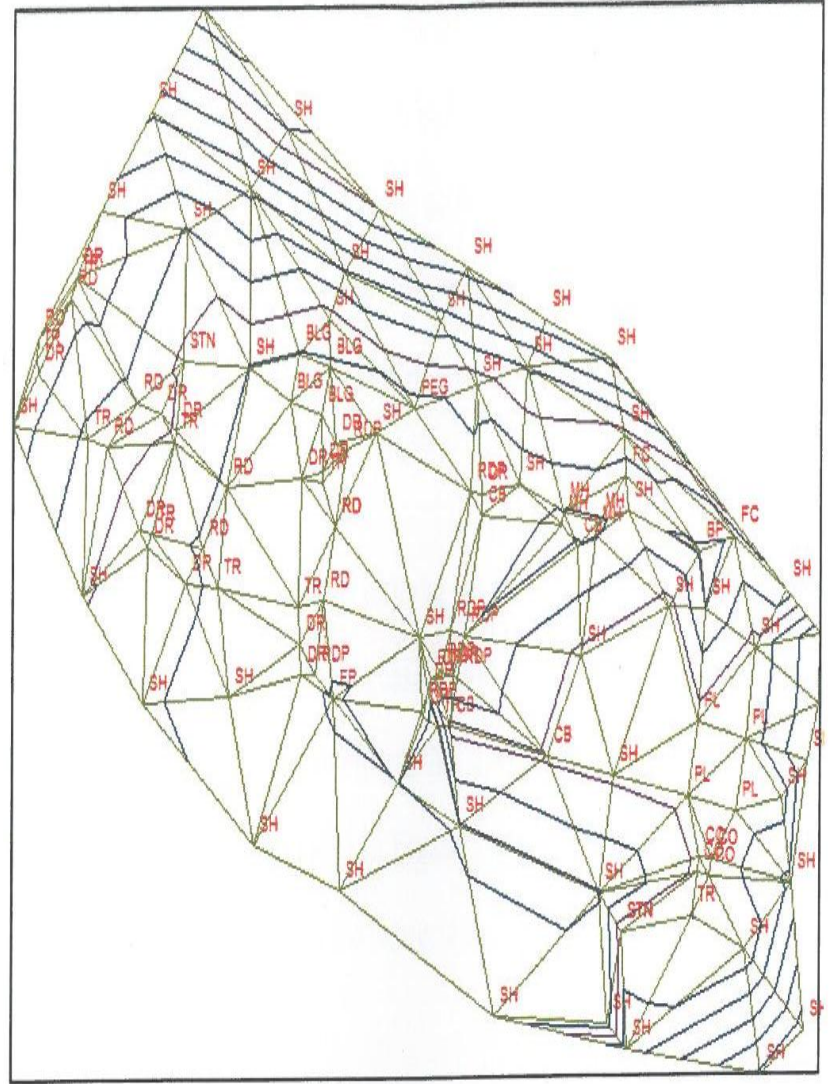

Figure 2 TIN Results from Civil Design Survey Software automation

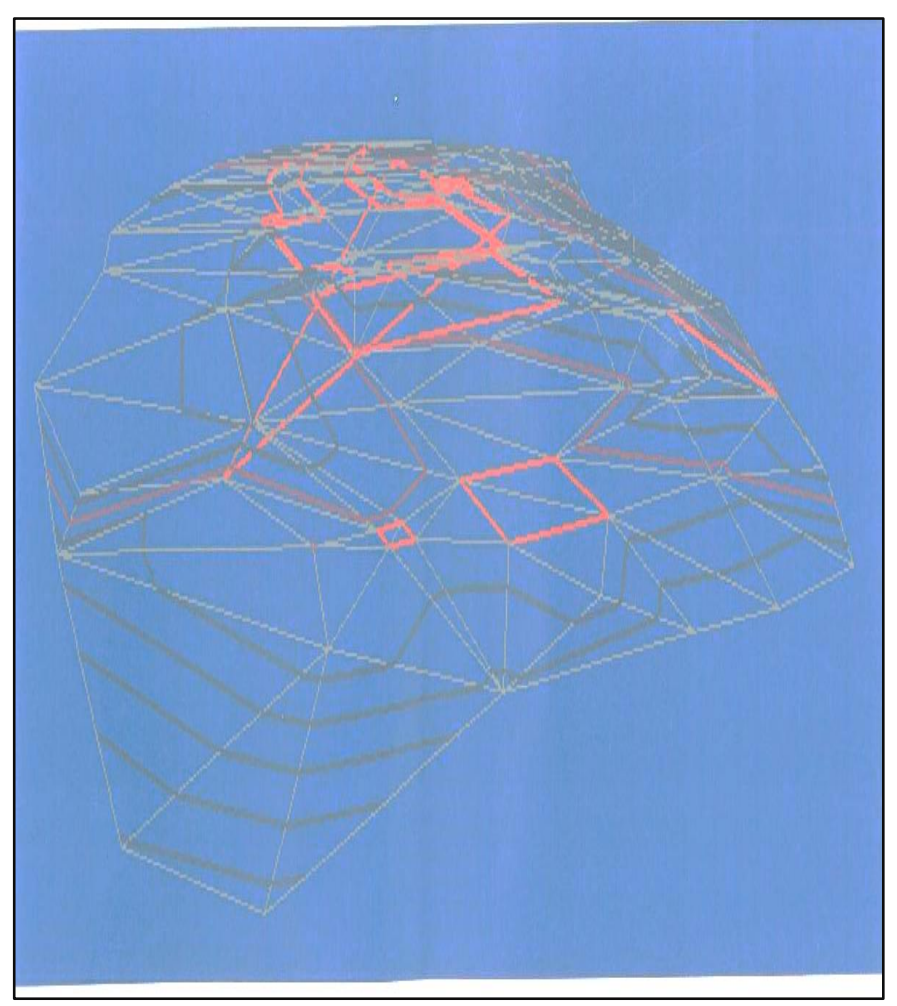

Figure. 3 3D from Civil Design Survey Software automation

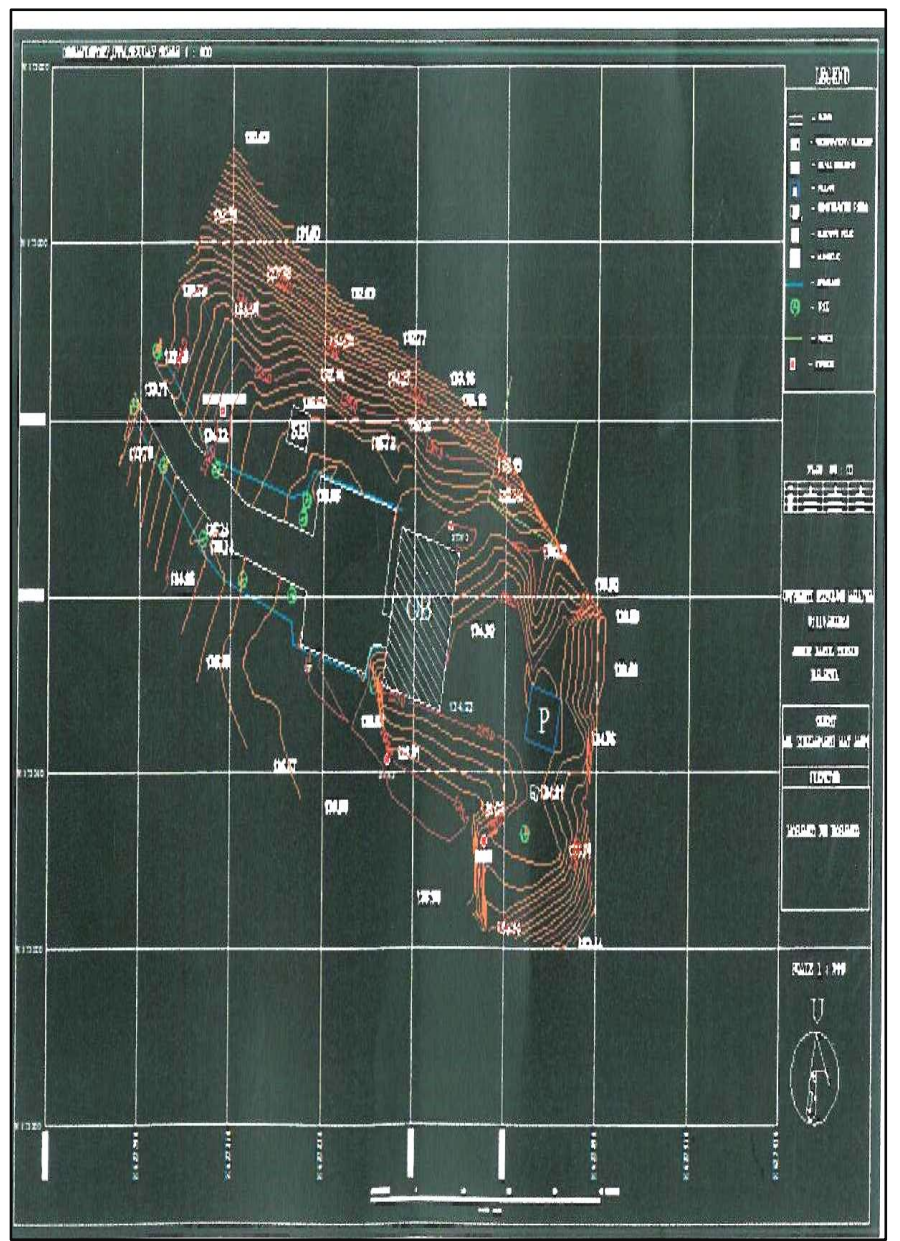

Figure 4 detail plan obtained from CDS and Imported into AutoCAD.

The results obtained from Carlson Survey 2009 Software are downloaded and processed in two forms. The two - dimensional detailed plan, GRID and TIN DTMs as well as the three dimensional models in both TIN and GRID formats are viewed in the 3D model viewer in Carlson Software.

As shown in the Figure 6 the TN results show a network of triangles connected by vertices of elevation points as surveyed from the field work and effectively depicting the terrain and topology of the study area. Figure 7 shows the three dimensional model of the TIN version of results as depicted by Fgure 6. 3D GRID representation Figure 9 tend to give a broader perspective of the topological qualities of the area surveyed while 2D GRID representation Figure 8 may sometimes have limited visual capabilities and may be hard to interpret or even un-interpretable to the untrained eye and no technical or experienced personnel. It is for this reason that the $3 \mathrm{~d}$ representations are normally preferred despite their demand for more storage space. 
M.F. EL Megrahi / Advances in Science, Technology and Engineering Systems Journal Vol. 2, No. 2, 11-18 (2017)

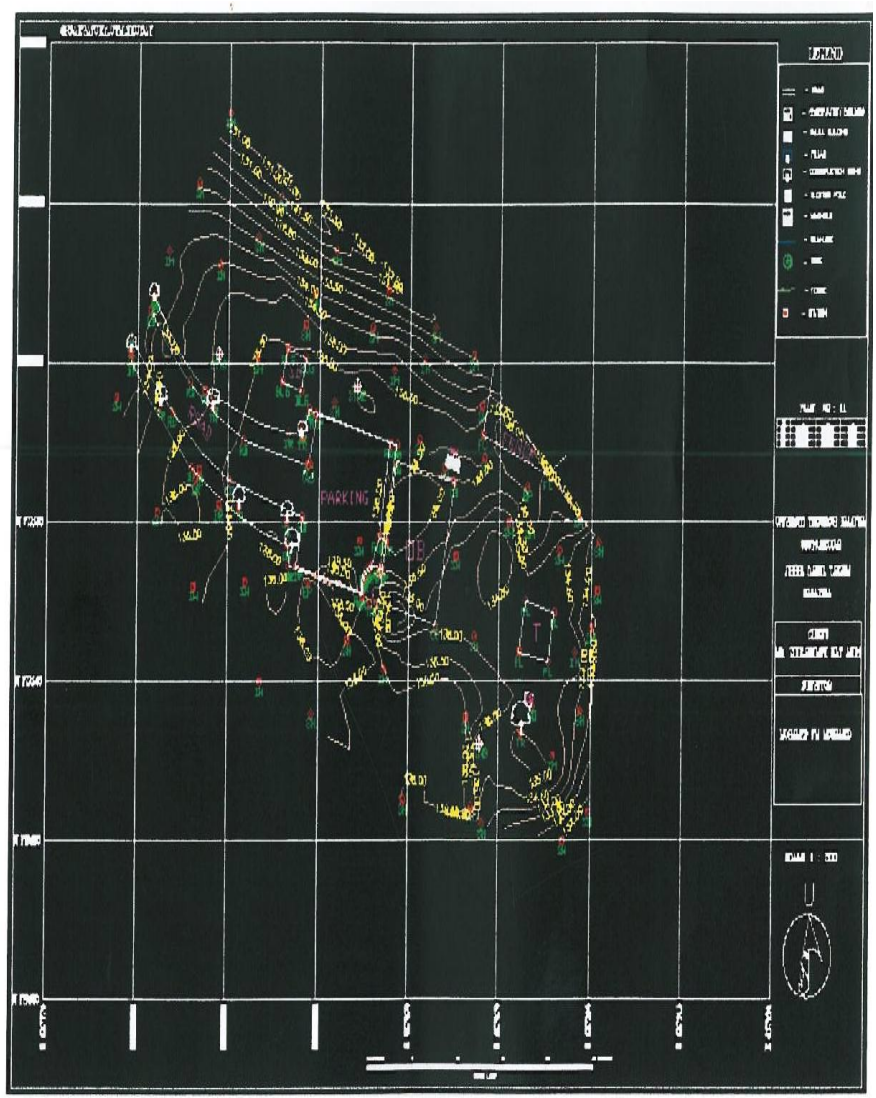

Figure 5 Detail plan from Carlson Survey 2009 Software.

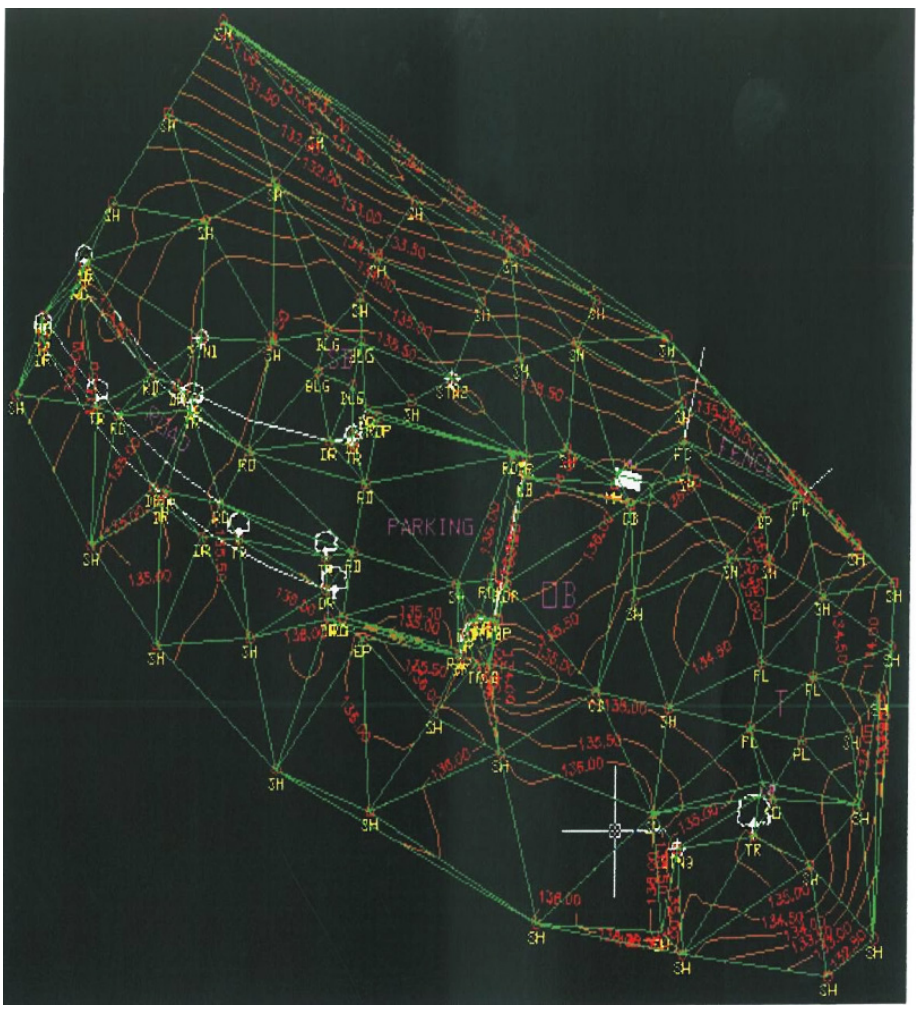

Figure .6 TIN representation in Carlson Survey 2009 Software.

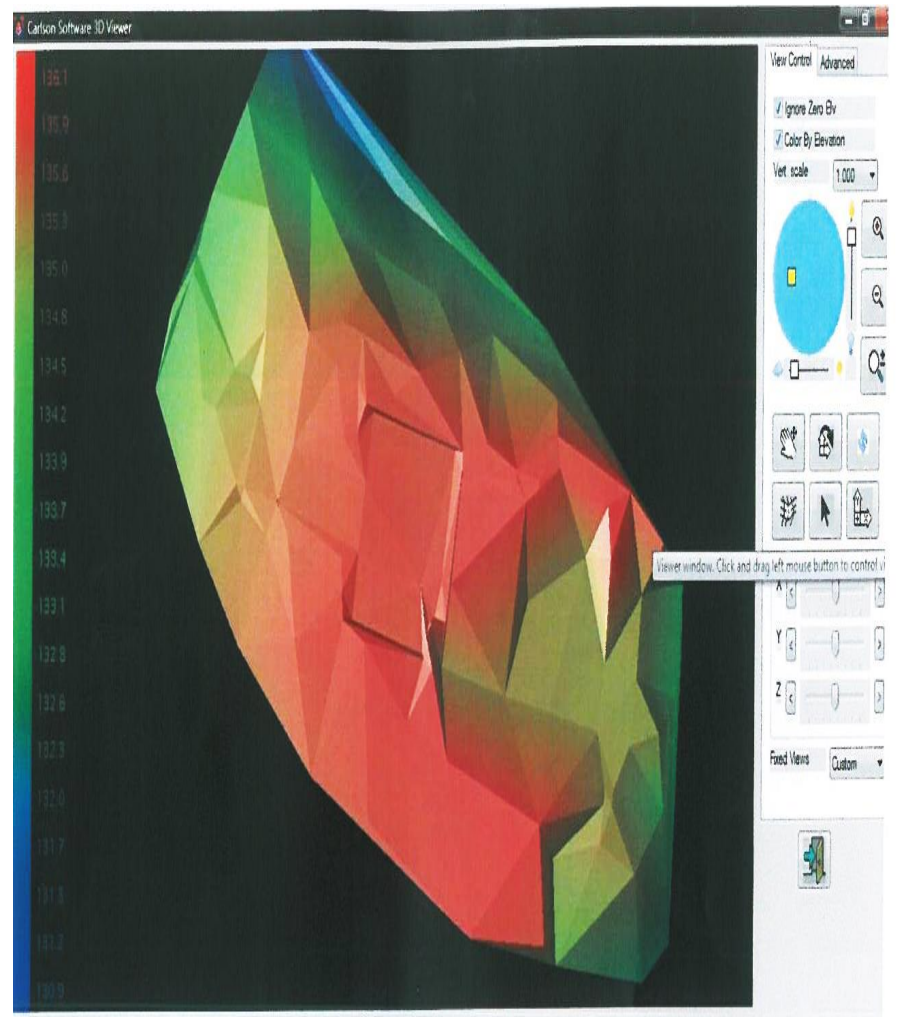

inoment

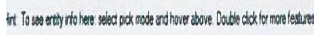

Figure 7 3D - TIN representation in Carlson Survey 2009 Software.

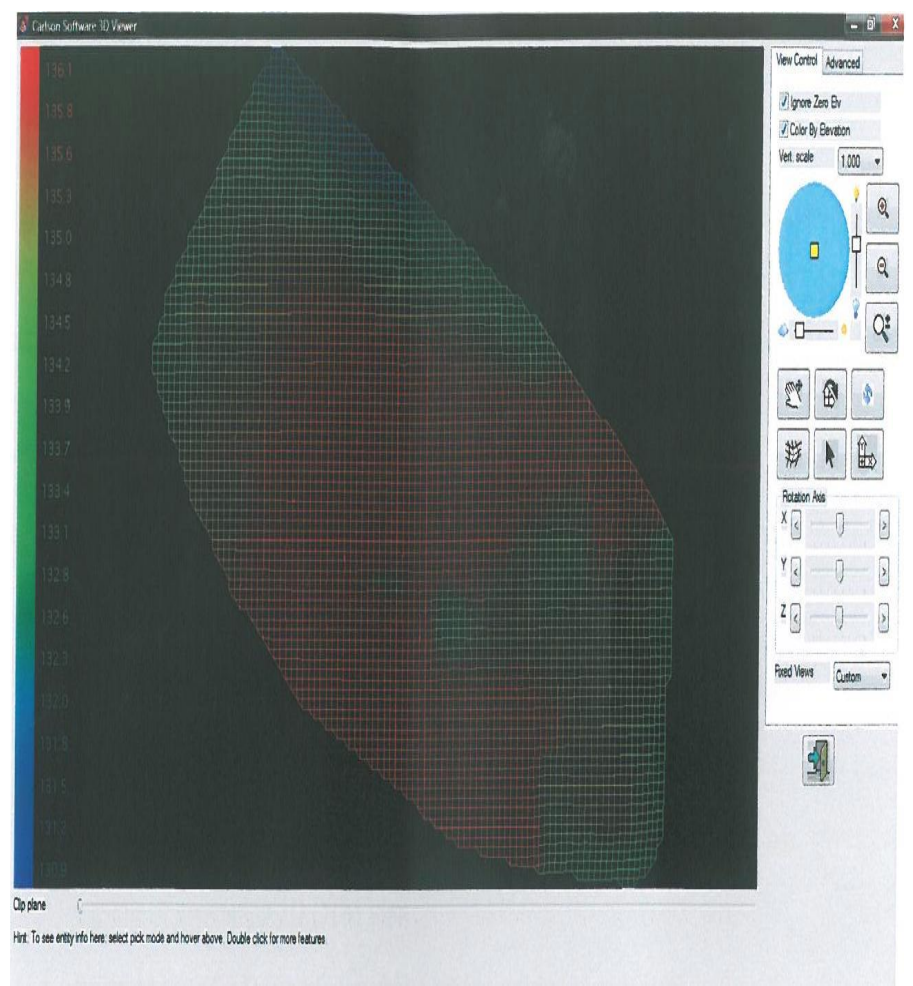

Figure 8 2D - GRID representation Carlson Survey 2009 Software. 
M.F. EL Megrahi / Advances in Science, Technology and Engineering Systems Journal Vol. 2, No. 2, 11-18 (2017)

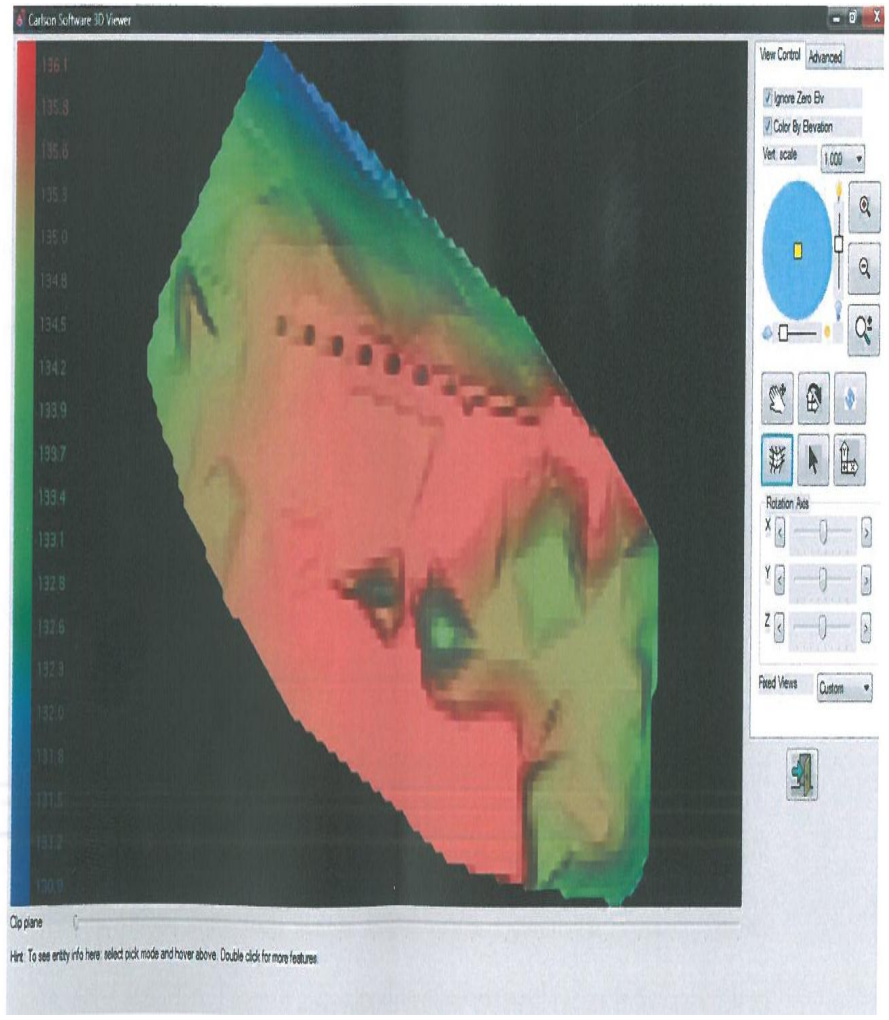

Figure 9 3D - GRID representation in Carlson Survey 2009 Software.

Carlson software is capable in downloading raw data from various types of total station and external data recorder module. This software support 100 percent raw data download from total station brand Leica, Geodimeter, Topcon, Nikon sokkia, Zeiss and Laser. It also supports other external recorder format such as SurCE, SurvStar, G2, Dozer2000, TDS, SDR, Surveyors Assistant and Geodat.

Raw data that had been downloaded to this software be processes stored as raw data format file. It has been discovered that Carlson 2009 Software is easier to understand the raw data format. Rows and lines from detail survey will be arranged and marked clearly as shown in Figure 10. Every detail point's information will be displayed completely as any point oriented, where it is faced, back station information, instrument and prism height, bearing, slope distance, vertical angle and detail code. The format is different with CDS software, where information on all detail is showed as basic in the stadia window like Figure 11. It showed all information needed in the survey data processing but needs great understanding to know the information array displayed.

Carlson Survey 2009 Software is not only capable of generating contour lines, but also capable of generating 3D dynamic view and from which height analysis can be carried out easily. Contour lines at field work can be generated without the user being prompted to manually generate the triangulation initially as required in the CDS software. This specification can fasten the generation of detail survey plan. Contour lines that have been

\begin{tabular}{|c|c|c|c|c|c|c|c|c|c|c|}
\hline \multicolumn{11}{|c|}{ 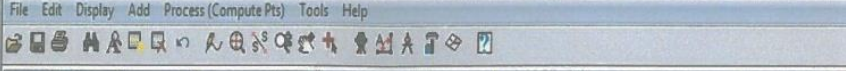 } \\
\hline & $T_{Y y}$ & & & & & & & & & \\
\hline 1 & - & $\Rightarrow \mathrm{p}$ & Pntilo & Morthing & & Easting & Elevation : & Dese & & \\
\hline 2 & PT & \pm 1 & & 173581.10 & & 627807.7810 & 135.0980 & STM1 & & \\
\hline 3 & $\mathrm{PT}$ & $\geqslant 2$ & & 173551.83 & & 627816.7980 & 135.6472 & $3 \pi / 2$ & & \\
\hline 4 & PT & \pm 3 & & 173592.11 & & 627865.6640 & 134.7540 & 5IN/3 & & \\
\hline 5 & & .10 & ocpt & Bspt & & Azi & Setazi & & & \\
\hline 6 & BK & \pm 1 & & 3 & & & 319.4520 & & & \\
\hline 7 & & $\exists$ & Mote & & & & & & & \\
\hline 8 & DS & \pm 0 & OC_ PT DE & CRIPTION: & SIN & & & & & \\
\hline 9 & . & \pm 1 & Instllt & Rodilt & & & & & & \\
\hline 10 & III & $\exists$ & 1.500 & 1.570 & & & & 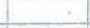 & & \\
\hline 11 & HII & 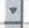 & & 1.500 & & & & & & \\
\hline 12 & & $\exists 0$ & OcPt & Fspt & Code & HorzAngle & SlopeDigt 2 & ZenithAng & Desc & \\
\hline 13 & ss & \pm 1 & & 2 & $A R=$ & 287.0710 & 30.633 & 88.3824 & STI & \\
\hline 14 & & -1 & InstHt & Rodit & & & & & & \\
\hline 15 & II & \pm & & 1.600 & & & & & & \\
\hline 16 & & -10 & OCPt & IsPt & Code : & HorzAngle & SlopeDist 2 & ZenithAng & Desc & \\
\hline 17 & ss & \pm 1 & & 1016 & $A R=2$ & 293.1624 & 70.196 & 89.0742 & BP & \\
\hline 18 & ss & $\exists 1$ & & 1017 & $A R=$ & 287.0710 & 30.633 & 88.3824 & PEG & \\
\hline 19 & ss & . 1 & & 1018 & ${ }_{A R}=$ & 298.2011 & 41.460 & 88.4249 & CB & \\
\hline 20 & ss & - 1 & & 1019 & $A R \cdot$ & 296.4839 & 54.448 & 88.5705 & $\mathrm{CB}$ & \\
\hline 21 & ss & 71 & & 1020 & $A R=$ & 119.1525 & 15.937 & 94.1916 & RD & \\
\hline 22 & ss & . 1 & & 1021 & $A R$. & 105.4020 & 19.429 & 93.3818 & RD & \\
\hline 23 & ss & $\exists 1$ & & 1022 & $A R=$ & 69.5146 & 7.132 & 92.1226 & RD & \\
\hline 24 & ss & 1 & & 1023 & ${ }^{A R}=$ & 63.4412 & 12.515 & 90.5619 & RD & \\
\hline 25 & ss & 71 & & 1024 & $A R=$ & 342.0642 & 12.209 & 87.1923 & RD & \\
\hline 26 & ss & 1 & & 1025 & AR $=$ & 0.4427 & 16.098 & 88.0151 & RD & \\
\hline 27 & ss & \pm 1 & & 1026 & AR $=$ & 314.4707 & 24.401 & 87.5611 & RD & \\
\hline 28 & ss & - 1 & & 1027 & $A R=3$ & 314.4707 & 24.400 & 87.5611 & RD & \\
\hline 29 & SS & - 1 & & 1028 & AR $\cdot 3$ & 327.2325 & 27.647 & 88.1305 & RD & \\
\hline 30 & SS & 1 & & 1029 & $A R=$ & 299.1432 & 22.791 & 88.0829 & RDP & \\
\hline 31 & ss & $\exists 1$ & & 1030 & $A R=$ & 336.3659 & 31.874 & 88.3613 & $\mathrm{RDP}$ & \\
\hline
\end{tabular}

Figure 10 Carlson software - RW5 file from data download

\begin{tabular}{|c|c|c|c|c|c|c|c|c|c|}
\hline \multicolumn{10}{|c|}{ I stadl.mp- } \\
\hline \multicolumn{10}{|c|}{ File Edit View Iable GoTo Qptions Window Help } \\
\hline \multicolumn{10}{|c|}{ 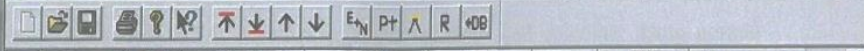 } \\
\hline & Type & Al\# & $\mathrm{Hz} \mathrm{Cir}$ & BS\# & Ht In & & $P C$ & Comments & $\triangle$ \\
\hline 1 & STN - & 1 & 627807.781 & 173581.107 & 135.098 & \multirow[b]{4}{*}{1.600} & \multirow{3}{*}{$\begin{array}{l}\text { STN } \\
\text { STN }\end{array}$} & & \\
\hline 2 & STN - & 3 & 627865.664 & 173532.115 & 134.754 & & & & \\
\hline 3 & AT/BS - & 1 & $319^{\circ} 4520^{\circ}$ & 3 & 1.500 & & & & \\
\hline 4 & SD/HT - & 16 & $293^{\circ} 1626^{\prime \prime}$ & $89^{\circ} 0742^{n}$ & 70.188 & & $B P$ & & \\
\hline 5 & $\mathrm{SD} / \mathrm{HT} \cdot$ & 17 & $287^{\circ} 0 r^{\prime} 10^{\prime \prime}$ & $88^{\circ} 3824^{\prime \prime}$ & 30.633 & 1.600 & PEG & & \\
\hline 6 & $\mathrm{SD} / \mathrm{HT} \cdot$ & 18 & $298^{\circ} 20^{\circ} 11^{\prime \prime}$ & $88^{\circ} 4249^{\prime \prime}$ & 41.460 & 1.600 & $C B$ & & \\
\hline 7 & SD/HT - & 19 & $296^{\circ} 48^{\prime} 39^{\prime \prime}$ & $88^{\circ} 5705^{\circ}$ & 54.448 & 1.600 & $\mathrm{CB}$ & & \\
\hline 8 & $\mathrm{SD} / \mathrm{HT} \cdot$ & 20 & $119^{\circ} 15^{\prime} 25^{\prime \prime}$ & $94^{\circ} 19^{\prime} 16^{\prime \prime}$ & 15.937 & 1.600 & RD & & \\
\hline 9 & SD/HT - & 21 & $105^{\circ} 40^{\prime 2} 20^{\prime \prime}$ & $93^{\circ} 38^{\prime 1} 8^{\prime \prime}$ & 19.429 & 1.600 & $\mathrm{RD}$ & & \\
\hline 10 & $\mathrm{SD} / \mathrm{HT} \cdot$ & 22 & $69^{\circ} 51^{\prime} 46^{\prime \prime}$ & $92^{\circ} 12^{\prime 2} 6^{\prime \prime}$ & 7.132 & 1.600 & $\mathrm{RD}$ & & \\
\hline 11 & SD/HT - & 23 & $63^{\circ} 44^{\prime} 12^{\prime \prime}$ & $90^{\circ} 5619^{\prime \prime}$ & 12.515 & 1.600 & $\mathrm{RD}$ & & \\
\hline 12 & SD/HT * & 24 & $342^{\circ} 0642^{n}$ & $87^{\circ} 19^{\prime \prime 2} 3^{\prime \prime}$ & 12.209 & 1.600 & $\mathrm{RD}$ & & \\
\hline 13 & SO/HT - & 25 & $0^{\circ} 44^{\prime} 27^{\prime \prime}$ & $88^{\circ} 0151^{\prime \prime}$ & 16.098 & 1.600 & $\mathrm{RD}$ & & \\
\hline 14 & SD/HT & 26 & $314^{\circ} 4707^{\prime \prime}$ & $87^{\circ} 5611^{\prime \prime}$ & 24.401 & 1.600 & $\mathrm{RD}$ & & \\
\hline 15 & SD/HT - & 27 & $314^{\circ} 4707^{\prime \prime}$ & $87^{\circ} 56^{611^{\circ}}$ & 24.400 & 1.600 & $\mathrm{RD}$ & & \\
\hline 16 & $\mathrm{SD} / \mathrm{HT} \cdot$ & 28 & $327^{\circ} 23^{\prime} 25^{\prime \prime}$ & $88^{\circ} 13^{\circ} 05^{\prime \prime}$ & 27.647 & 1.600 & $\mathrm{RD}$ & & \\
\hline 17 & $\mathrm{SD} / \mathrm{HT} \cdot$ & 29 & $299^{\circ} 1432^{\prime \prime}$ & $88^{\circ} 08^{\prime \prime} 29^{\prime \prime}$ & 22.791 & 1.600 & RDP & & \\
\hline 18 & SD/HT - & 30 & $336^{\circ} 3659^{\prime \prime}$ & $88^{\circ} 36^{13}$ & 31.874 & 1.600 & RDP & & \\
\hline 19 & $\mathrm{SD} / \mathrm{HT} \cdot$ & 31 & $296^{\circ} 08^{\prime 2} 5^{\prime \prime}$ & $88^{\circ} 5255^{\prime \prime}$ & 39.525 & 1.600 & RDP & & \\
\hline 20 & $\mathrm{SD} / \mathrm{HT} \cdot$ & 32 & $323^{\circ} 03^{\prime 4} 43^{\prime \prime}$ & $88^{\circ} 58^{3} 38^{\circ}$ & 43.414 & 1.600 & RDP & & \\
\hline 21 & SD/HT $\cdot$ & 33 & $312^{\circ} 43^{\circ} 03^{\prime \prime}$ & $88^{\circ} 43^{4} 48^{\prime \prime}$ & 42.189 & 1.600 & RDP & & \\
\hline 22 & SD/HT . & 34 & $319^{\circ} 06^{\circ} 00^{\circ \prime}$ & $88^{\circ} 53^{\prime \prime} 33^{\prime \prime}$ & 42.448 & 1.600 & RDP & & \\
\hline 23 & SD/HT - & 35 & $317^{\circ} 3756^{\circ}$ & $88^{\circ} 54^{\prime} 42^{\prime \prime}$ & 43.077 & 1.600 & RDP & & \\
\hline 24 & $\mathrm{SD} / \mathrm{HT} \cdot$ & 36 & $316^{\circ} 1807^{\prime \prime}$ & $88^{\circ} 44^{\prime} 31^{n}$ & 45.192 & 1.600 & RDP & & \\
\hline 25 & SD/HT - & 37 & $311^{\circ} 5222^{\prime \prime}$ & $88^{\circ} 41^{15} 7^{\prime \prime}$ & 43.895 & 1.600 & $\mathrm{RDP}$ & & \\
\hline 26 & $\mathrm{SD} / \mathrm{HT} \cdot$ & 38 & $293^{\circ} 5735^{\prime \prime}$ & $87^{\circ} 4529^{\prime \prime}$ & 18.808 & 1.600 & BLG & & \\
\hline 27 & SD/HT $\cdot$ & 39 & $293^{\circ} 14^{\prime} 07^{\prime \prime}$ & $87^{\circ} 31^{\prime} 03^{\prime \prime}$ & 14.453 & 1.600 & BLG & & \\
\hline 28 & SD/HT - & 40 & $277^{\circ} 39^{9} 40^{\circ}$ & $88^{\circ} 00^{4} 45^{n}$ & 15.265 & 1.600 & BLG & & \\
\hline 29 & SD/HT $\cdot$ & 41 & $281^{\circ} 10^{\prime} 43^{\prime \prime}$ & $88^{\circ} 1609^{\prime \prime}$ & 19.246 & 1.600 & BLG & & 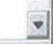 \\
\hline For & Help, press & & & & Metres & \pm 1 & Whole Circh $\nabla$ & & SCRI \\
\hline
\end{tabular}

Figure 11 CDS software - the stadia file 
generated can be fully manipulated like line smoothing, labeling, color changing, line width and type. All functions are in contour menu on DTM-contour module without worrying if contour lines damaged and there is no need to reprocess the contour.

Three dimensional DTM views can be generated via Carlson Survey 2009 Software. Accuracy on DTM generated is high and the users are able to have the option to choose the model method such as triangulation, kriging, polynomial, and least root mean square (can be viewed on Figure 6 and 8) However, CDS software can only use triangulation method to generate DTM. Dynamic three dimensional can be viewed on 3D viewer window and users can rotate $\mathrm{X}, \mathrm{Y}$ and $\mathrm{Z}$ axes to view $3 \mathrm{D}$ clearer.

3D view generated by Carlson Survey 2009 Software (Figure.7) can be shown by color representations foe every elevation. With different colors, users can make height analysis much easier only by using bare eye inspection, while CDS software is only capable of generating $3 \mathrm{D}$ view in one color (Figure 3) which is a major difference especially for data representation to non-skilled or nontechnical personnel.

The usage of AutoCAD platform in this software makes graphical editing works much easier and faster. Users who have been familiar with AutoCAD environment will discover that Carlson software can help then in editing the plan two time faster. This because of the AutoCAD handicap such as LISP routine and editing toolbars plus new specifications on Carlson survey 2009 software, i.e. Annotate menu which helps completing detailed plan faster. Carlson Survey 2009 Software has the features that can help to draw legend, north direction, map frame, and grid boxes automatically. These features are not available in CDS software.

In the research, Carlson Survey 2009 Software is capable to plot any plan with any scales. This software uses interface plotter from AutoCAD software. In order to do checking, user can view the plans contain before it is actually platted using Full Preview button for whole checking and Partial Preview foe partial checking. Table 1 shows a summary of the comparison between six aspects that are needed in any survey software to generate detail plan survey.

\section{Conclusions and recommendations}

Time foe processing: whereas both software are capable of producing nearly identical results, the time for processing required for both greatly difference, In CDS the processing is done automatically in the CDS software suite but later needs to be exported to a CAD software such as AutoCAD for further and more refined editing this makes the process longer the Carlson Survey Software where the software is CAD based and tools for editing and processing are combined in the some suite.

Table 1 Comparison between Carlson Survey 2009 Software and CDS software

\begin{tabular}{|c|c|c|}
\hline Specification & Carlson Survey 2009 & $\begin{array}{l}\text { Civil Design and } \\
\text { Survey (CDS) }\end{array}$ \\
\hline $\begin{array}{l}\text { Data } \\
\text { download }\end{array}$ & $\begin{array}{l}\text { Capable to download from } \\
\text { various format of total station } \\
\text { and electronic data recorder. }\end{array}$ & $\begin{array}{l}\text { Also capable to } \\
\text { receive various } \\
\text { format of total } \\
\text { station and } \\
\text { electronic data } \\
\text { recorder }\end{array}$ \\
\hline \multirow{3}{*}{$\begin{array}{l}\text { Data } \\
\text { processing }\end{array}$} & $\begin{array}{l}\text { Easy to understand raw data } \\
\text { format In Raw Editor RW5 } \\
\text { windows }\end{array}$ & $\begin{array}{lr}\text { Need good } \\
\text { perception to } \\
\text { understand raw } \\
\text { data format in } \\
\text { stadia window }\end{array}$ \\
\hline & $\begin{array}{l}\text { Prepares six choices to do } \\
\text { coordinate calculation i.e. } \\
\text { latit dipat calculations, angel } \\
\text { adjustment, compass, } \\
\text { Crandall, transit and LSA }\end{array}$ & $\begin{array}{l}\text { Prepares only two } \\
\text { coordinate } \\
\text { calculations } \\
\text { method i.e. latit } \\
\text { dipat calculation } \\
\text { and LSA. }\end{array}$ \\
\hline & $\begin{array}{l}\text { Using Field to Finish } \\
\text { command to process lines, } \\
\text { polygon and points } \\
\text { automatically. }\end{array}$ & $\begin{array}{lr}\text { Using } & \text { Feature } \\
\text { Code } & \text { Library } \\
\text { command } & \text { to } \\
\text { process } & \text { lines. } \\
\text { Polygons } & \text { and } \\
\text { point } & \\
\text { automatically. }\end{array}$ \\
\hline \multirow{3}{*}{$\begin{array}{l}\text { Contour and } \\
\text { DTM } \\
\text { generation }\end{array}$} & $\begin{array}{l}\text { Generate contour without } \\
\text { prompting user to generate } \\
\text { triangulation lines. }\end{array}$ & $\begin{array}{l}\text { Requires user to } \\
\text { generate } \\
\text { triangulations } \\
\text { lines before } \\
\text { contour }\end{array}$ \\
\hline & $\begin{array}{l}\text { 3D DTM is generated by } \\
\text { triangulation, Kriging, } \\
\text { Polynomial and least root } \\
\text { mean square methods. }\end{array}$ & $\begin{array}{l}3 \mathrm{D} \text { DTM is } \\
\text { generated by } \\
\text { triangulation } \\
\text { method only }\end{array}$ \\
\hline & $\begin{array}{l}\text { DTM is represented with } \\
\text { different color based on } \\
\text { height. this will make height } \\
\text { analysis much easier even by } \\
\text { bare eyes. }\end{array}$ & $\begin{array}{l}\text { DTM is } \\
\text { represented only } \\
\text { by green color. } \\
\text { Height analysis } \\
\text { by bare eyes is } \\
\text { nearly impossible }\end{array}$ \\
\hline $\begin{array}{l}\text { Graphical } \\
\text { editing }\end{array}$ & $\begin{array}{l}\text { Uses AutoCAD interface for } \\
\text { CAD graphical editing }\end{array}$ & $\begin{array}{lr}\text { Uses internal } \\
\text { CAD. } \\
\text { capability }\end{array}$ \\
\hline Plan Plotting & $\begin{array}{l}\text { Capable to plot final plan } \\
\text { with any wanted scale }\end{array}$ & $\begin{array}{l}\text { Also capable to } \\
\text { plot final plan } \\
\text { with any wanted } \\
\text { scale }\end{array}$ \\
\hline $\begin{array}{l}\text { Format } \\
\text { changing }\end{array}$ & $\begin{array}{l}\text { Changes to dxf. Format is not } \\
\text { necessary as it uses } \\
\text { AutoCAD platform }\end{array}$ & $\begin{array}{l}\text { Changes to dxf. } \\
\text { Format is } \\
\text { necessary for } \\
\text { further editing }\end{array}$ \\
\hline
\end{tabular}


User input required: it is fairly difficult to draw a line between CDS and Carlson software when it comes to user input and expertise necessary but it is relatively and easy to conclude that in Carlson survey 2009 software the user is required is less than that necessary from start to finish for a project as compared to that required in CDS software however this question may be subjective the individual user and comfort as well as back ground of expertise. Civil Engineers used to working in AutoCAD will find Carlson Survey 2009 Software relatively easier compared to the CDS while surveyors may find using CDS easier in some cases despite its other shortcomings.

Suitability of Results: this aspects of the two software is totally subjective to the user requirements but based on the data and processing carried out in this project as well as the vast function, commands and editing capabilities available to user in Carlson Survey 2009 Software, the researchers is based to the reasoning that the result form Carlson Survey 2009 Software are most suitable than those that are obtained from CDS Software but this still remains to the user requirements and personal preferences of individual users.

From the analysis carried out in this research , the applications and capability of automation in engineering surveying has been studied and understood with reference to total station and two software namely ; CDS and Carlson survey 2009 from field data collection until the production of detailed maps.

Emphasis in the research was placed on the understanding and applications of Carlson survey 2009 software and its functionalities such as survey, surface and COGO menus and these have all, at one time applied to complete one task .

Some of the tasks :

1. Data collection, conversion and processing or edit directly via the edit process raw data file.

2. Contour plan and DTM generation

3. Plotting at different scales

The application were all effectively and impressively done in one package making Carlson survey 2009 software ideal for today's robust survey activities .

The platform of Carlson survey 2009 software given an ideal characteristic for user familiar with AutoCAD and easy to learn .also offered to be able to create contour plans and DTM easier and less time. The incorporated facilities such as LISP routine and toolbars for editing along with the addition of some new features in Carlson survey software itself for instance annotate menu used in classification .

Carlson survey 2009 software had ideal qualities for presentation of data in three dimensions (3D) as digital terrain models both smoothly and accurately based on the software's algorithm forms modeling such as triangulation, Kriging, polynomial and least squares estimation methods.

A comparison between CDS software to Carlson survey 2009 software reveled that while CDS has the capability of effectively representing the same it is limited to one method (triangulation) whereas Carlson survey is endowed with numerous methods even the gird method.

Carlson survey 2009 software is dedicated to providing the finest software to lands surveyors, civil engineers, mining engineers, and land development professionals making it ideal for use in today survey needs ranging where time and resources have to be effectively and efficiently managed.

The recommendations list drawn in this study as:

1. Carlson survey 2009 software to be applied and adopted as the overall engineering survey software by surveyors in Libya due to the numerous advantages and functionalities it presents to surveyors and engineers.

2. GIS module and menu in Carlson survey 2009 software can be used to establish the database for the engineering surveys on numerous project in Libya from road design to construction and can manage all contour plans, documents, coordinates and heights information, traverse and tachometry data and also boundaries marks location status. DTM can be used as the 3D base map for managing the information .

3. survNet menu for network least squares calculation which is essential for raw survey notes reduction. SuevNet handles any combination of total station, GPS and level loop measurement.

4. Carlson survey 2009 software combined the surveyors preferred language of point based coordinate geometry (COGO) commands within the AutoCAD drawing environment better than any other survey software in AutoCAD.

5. Hydrology module can be used in hydrographic survey to determine the thalweg for boundaries located along a river.

6. More research and studies be carried out in the engineering survey automation filed especially in other undeveloped in countries like Libya .

7. Used Carlson survey 2009 software in implementation and building of survey and information database from acquired and information processed which would in turn be used as a GIS or land information system for surveyors .

\section{References}

[1] Anderson, J., Mikhail, E. (1998) Surveying Theory and Practice, 7th Edition (pp.44-52). Boston: WCB/McGraw-Hill.

[2] Carlson Survey 2009 Embedded AutoCAD, User's manual.

[3] Constructive surveying and layout. A step by step filed engineering methods manual by Wesley G. Carwford . 1995.

[4] Craymer M.R., Wells D.E., Vanicek P. \& R.L. Devlin, 1990, Specifications for urban GPS surveys. Surveying and Land Information Systems, 50(4), 251259. 
M.F. EL Megrahi / Advances in Science, Technology and Engineering Systems Journal Vol. 2, No. 2, 11-18 (2017)

[5] Elementary surveying 6th Edition 1977. Russell C. Brinker \& paul R. wolf Thomas y. Crowell, Harper \& Row , Publish ers- New York

[6] Jennifer DiBona ( 2013) Using Field to Finish with Carlson Survey \& SurvCE, Maryland Society of Surveyors 2013 Fall Conference.

[7] Jennifer DiBona (2014), New Jersey SurvCon 2014 Field to Finish And Surface Modeling with Carlson Survey

[8] Jennifer DiBona (2016), Field to Finish for Survey and GIS Collection, PSLS Surveyors' Conference 2016 Pennsylvania Society of Land Surveyors.

[9] Jivall L., 1992, GPS for geodetic control surveying in Sweden, 6th Int. Geodetic Symp. On Satellite Positioning, Columbus, Ohio, 17-20 March, 501-510.

[10] Map Use and Analysis .4th edition. 2001 campbell , J, McGraw- Hill. Higher education. 130, New York.

[11] Surveying for engineering 3th edition 1994. j. Uren - department of civil engineering university of leeds .\& W.F,Price- department of civil engineering university of Brighton .

[12] U.S. Army Corps of Engineers, Engineer Manual EM 1110-1-1002, Survey Markers and Monumentation, 1 March 2012

[13] U.S. Army Corps of Engineers, Engineer Manual EM 1110-1-1003, NAVSTAR Global Positioning System Surveying , 28 February 2011

[14] U.S. Army Corps of Engineers, Engineer Manual EM 1110-1-1005, Control and Topographic Surveying, 1 January 2007 .

[15] User Guidelines for Single Base Real Time GNSS Positioning, Version 2.1(2011), William Henning, National Oceanic and Atmospheric Administration, National Geodetic Survey. 